\title{
Approaches to developing the design code as part of the modern city improvement standard
}

\author{
Tatyana Karakova ${ }^{1, *}$ \\ ${ }^{1}$ Samara State Technical University, Institute of Architecture and Civil Engineering, 194, \\ Molodogvardeyskaya St., 443001, Samara, Russia
}

\begin{abstract}
The article considers methodological approaches to solving complex environmental problems which play a significant role in formation of the authentic image of the city, the mentality of its citizens, as well as in improving the consumer qualities of the city's depressed areas. The novelty of the author's approach is manifested in interdisciplinary consideration of the problems, in understanding of urban space formation as a system of interacting and intersecting social, economic, urban, and natural ecological function fields, forming together the physical space of the city, which, in turn, is presented by a variety of environments with individual characteristics. The development of the modern standard of area improvement is perceived by the author through the implementation of the main provisions of the city environmental land register that could provide a solution to a broad range of environmental problems.
\end{abstract}

\section{Introduction}

The issue of developing a design code for the modern standard of city area improvement is connected with the need to address a wide range of questions while maintaining and, often creating, its unique personalized image. In addition to a large number of ill-provided urban areas in Russian cities, the problem is complicated by the fact that the existing residential territories of the majority of large Russian cities have been overbuild with large massive prefab constructions. In overall housing, their share accounts to 60 to 80 percent. The city of Samara is no exception. Its layout developed in an extremely peculiar way: stripped pattern of large groups of prefab housing is observed in the central, middle and peripheral parts of the city. If the periphery contains monotonous and repetitive blocks of bearing-wall structures, the central area of the city fragmented by such buildings produces negative compositional contrasts, which are often contradictory to architectural harmony. Racing of the service sector and business into the city's central areas, active changes in the structure and quality of consumer interests have become reasons for diluting the functional-spatial environment of residential areas in the middle and peripheral areas of cities. Sociallyoriented activities of an environmental architect and designer should be focused today on the search for active interaction between the residents in the area, creating a functional space capable of ensuring the ease of tension and escape from sharp division of the city into comfortable and ill-provided territories. Of particular importance is research and

\footnotetext{
${ }^{*}$ Corresponding author: t.karakowa@mail.ru
} 
typological systematization of rehabilitation techniques for the depressed areas of the urban environment and, in particular, the pedestrian areas of central, middle and peripheral residential zones of the city. Interdisciplinarity of the problem predetermined the wide range of objectives dealt with by the scientists, whose works address the following issues: formation of a new social and economic paradigm of the urban environment in the works of P. Bourdieu, Ovsyannikova, V. A., Goltz, G. A., Toffler, E. et al.; the problem of formation of the urban environment social field studied by K. Lynch, Krivoruchenko, Y. I., Golova, A. G., Prokhorov, B. B., Semenova, T. V., Ionin, L. I. etc.; special features of architectural formation of the urban environment and its perception in the works of Rappoport, A. G., Yargina, Z. N., Shimko, V. T., Efimov, A. V., Glazychev V. L., Sotnikova, I. V., Akhmedova L. S., Teryagova, A. N., Smolenskaya, E. O., Barova, K. D. et al.; exploring natural and visual ecology of the urban environment studies by D. Gibson, L. Ronchi, Tetiora, A. N. and etc.

\section{Methods}

Modern approaches to typological analysis of the urban environment as a system of interaction of economic, social, urban and natural-ecological functional fields form in aggregate the physical space of the city, which is a product of socio-economic construction of spatial connections of the population. The current economic paradigm of Russia determined the emergence of new socio-economic categories, among which is the evolution of "representative areas", residential property market and of such attribute of material prosperity as a concept of "prestigious location". The structure of the Russian city economic field reflects the city resident's scope of capabilities and is associated with the material and spatial segmentation of the population depending on the form of ownership and the location of real estate within a highly comfortable urban environment. For comparison, the area of high interest is the spatial distribution of economic and social fields as exemplified by the city of Paris [1] when the features of arranging the representative service facilities (theaters, art galleries, shopping facilities, newspaper offices of economic, political and intellectual content) in space, as well as the deployment of prestigious housing, were studied in line with the graphic-analytical method. The analysis showed that the elite housing areas are located at the boundaries of the zones with increased number of entertainment and shopping facilities with their position drawing near the Seine embankment. From types of theaters described (tabloid, neutral and intellectual), central regions mostly attracted those of the first type. Intellectual stages were mostly located in the peripheral areas of the city, which illustrates the contrast between "commercial" and "noncommercial" within the city space. Over the last 20 years the prestigious residential areas have been established in Russian cities, but the context is such that the peripheral areas are actively transforming into bedroom communities with low quality of consumer environment and poor service area.

Developing the environmental land register ensures a comprehensive solution of such topic-related issues as differentiation of the city's three-dimensional environment into color zones, the development of color enhancement of streets and landscaping, identification of problem areas within the urban space visual field, the development of regulations for coloring facades and coloring schemes for routing of public transport; the development of landscape design as a powerful tool for greening the urban environment, the integration of architectural objects with natural environment, providing the basis for the formation of "place recollection" in the minds of citizens; the lighting design of pedestrian areas of the city environment in relation to public facilities and centers, pedestrian transit routes, transport routes, recreational areas, residential courtyards, as well as the representative (guest) routes as a means of socialization of the population, increasing the promotion of 
architectural styles and the investment attractiveness of the urban environment areas; the optimization of temporary retail trade facilities in the city, their typology and functional specialization, the formation of fragmentary shopping streets (trade corridors) in various parts of the city, the arrangement of social activity centers in the peripheral areas of the city, the design of entrances to the trading facilities; dislocation and the content of the outdoor advertising in the city; objects of art design and sculptures, street art in the urban environment, the designing rehabilitation of the typical buildings' facades within the representative parts of the urban environment, public transport stops, entertainment, parking and exhibition facilities, bicycle parking lots, types of fences and their design, street navigation; compositional and spatial design of festive decorations for streets and squares, the functional and spatial, scenario-oriented and artistic approach for year-round use of city squares for cultural events, etc. [2,3,4].

The environmental land register has allowed not only to solve a number of social and urban problems of the Samara city, but also to blend well in the all-Russian strategy of war on illegal placement of temporary corner shops. For example, in St. Petersburg, the City Government Resolution № 1045 of 27.09 .2012 on placement of small retail shops entered into force on January 1, 2013. The document contains the procedure for formulation and approval of the configuration plan for placing temporary retail trade facilities on state land owned by St. Petersburg, and on those areas where state ownership is not classified. From 2011 Moscow actively implements the Provisions of the Moscow Government Decree No. 26- ПП of February 3, 2011 (as amended on 26.03.2012) On Placement of Temporary Trade Facilities Located in Moscow on Land, in Buildings and Facilities Owned by the State. If in 2010 the number of such facilities amounted to 14,600 units, in 2016 it decreased to 6140 units. Deployment of new facilities is under control, and the established directory allows the City Administration to provide entrepreneurs with turnkey corner shops tracking even the functional trade specialization. Certain categories of public service facilities are developing as well: 1377 summer coffee-shops were serving customers in 2010 in Moscow, and in 2016 the number grew to 2,000. The Federal Law No. 258-Ф3 of July 13, 2015 is being actively implemented [5]. In the last 3 years in Samara, we eliminated more than 1,500 illegally placed temporary retail facilities in the form of corner shops destroying the artistic image of the city $[6,7,8]$.

For the city of Samara, environmental land register issue has been addressed within a framework of the municipal contract Regulations on the Planned Development of the Territory Including Density and Parameters of Territory Development, Characteristics of Social Security Systems Needed for Their Development on the Ground of Optimization of Temporary Retail Facilities Placement on the Territory of the Samara City (2013) directed by T. V. Karakova. The results of this work included not only the scheme for optimization of retail facilities placement, but also a catalog of temporary corner shops adapted to the stylistic characteristics of different city areas in terms of architecture and composition. Active work on the design of entrances to the service facilities located in the ground floors of residential buildings is continuing. Of particular importance are the objects of trade and services located within the representative "guest routes" dedicated to the upcoming FIFA World Cup 2018. By shaping the unique street image, the entrances to such facilities attract visitors from a number of residents and city visitors, feature original installations and narrative compositions. If within the boundaries of the urban center such phenomenon is accompanied by formation of the visual basin including significant architectural objects, elements of land improvement and landscaping, in the remote areas entrances to shops and offices designed by the architect and designer play an important compositional, shaping and commercial role. The forum on the problems of urban environment, held in Moscow on September 12, 2016, identified key area of land and urban environment improvement, stated that the improvement of urban environment is a national priority. 
The forum emphasized that working with urban environment today means fighting for state competition between cities and attracting investment, the choice of the place of residence for people. This is an urgent problem of creating a comfortable environment where the daily life of urban residents flows, whose share is $3 / 4$ of the total country population. Ultimately, we are talking about the level and quality of their life $[9,10]$.

\section{Results}

The analysis showed that the scope of the general plan of city development does not allow us to consider the questions of environmental arrangement, however, the quality of the material and spatial environment, the preservation and evolution of its value-oriented environment, its architectural and landscape composition, its decoration and lighting design and other characteristics accounting for its performance become the object of town planning $[9,10,11]$. Town planning as a process of imposing restrictions (regulations) on the use of city areas and the property within each of the areas of the considered urban environment is enshrined in the documents on city zoning. The concept of "urban environmental land register" was included in the overall urban development aspect of the city development plan. The register addresses the results of the qualitative status check of the urban environment areas, carrying out diagnostic procedures, contains recommendations on the prospects of environmental transformations, including compositional and coloristic characteristics of the urban development, questions of placement and content of outdoor advertising, lighting and landscaping, the location of sculptural compositions etc. Cadastral evaluation allows us to predict the consumer status and the expected amount of income received in different parts of the urban environment [12].

Decree of the Head of Samara City No. 1093 On the Development of TargetedProgram: Environmental Land Register of Samara City of December 19, 2008 enshrined the decision to establish the abovementioned system, the idea that was born while designing the project of the guest route in Leninsky district of Samara city. Later, the concept of environmental land register for Samara city was included in the program document titled Strategy of Socio-Economic Development of Samara up to 2025.

The main objective of the environmental land register is to improve the functional and aesthetic qualities of the urban environment, to arrange rational use of material resources acquired from various types of proprietors for the improvement of the city, its paving, planting, watering, repairing urban facilities. Developing the environmental land register means achieving maximum socio-cultural effect which leads to the disappearance of the city's periphery-center opposition in terms of consumer features, while maintaining the natural differences in their degree of centrality.

\section{Discussion}

Today, the global city management practice is following the way of forming a holistic society that meets the needs of different segments of its population, explores social issues of the architectural environment, frames the technique of architectural sociology, develops the principles of social rehabilitation of the peripheral areas of large cities. The area of interest is the experience of Germany where, on the territory of former GDR, the government is consistently solving socio-political tasks related to the rehabilitation of prefab housing and creation of highly comfortable residential environment: panels from dismantled buildings are utilized for construction of detached two-storied houses, parking lots; blocks of flats are re-designed into luxury houses with expensive apartments. The program has been widely implemented in Germany, the Netherlands and Sweden [13]. 
The interdisciplinary studies developed across architecture, urban planning, psychology, geography, economics are now turning into those of paramount importance from a theoretical point of view $[14,15,16]$. The researchers working in these areas are united in the opinion that the features of lives of city residents, in one way or another, are connected with the perception of urban space and the effects of urban life, with the ability to cover city distances, to assess the attractiveness of the town center, to experience such psychological states as "urban stress", "a sense of provinciality" and others. Thus, the urban environment, being a constantly perceived visual factor, has a significant impact on the mental well-being of citizens, and the measure of the town's provinciality has to do with the parameters corresponding to such components of "urban mentality" as quantitative and qualitative variety of the architectural objects that are most significant for the majority of citizens, their ensemble, the presence of high-rise buildings, the consumer value of urban environment, comfortable transport and pedestrian infrastructure and the developed accessibility of service facilities, wide range of their services, high level of city improvement in the form of paving, landscaping and irrigation, a variety of stylistic and a coloristic elements in the city environment, the presence of historical, cultural and architectural heritage, recording of historical place names, the existence of urban traditions, etc. [17]. Active transformation of public city areas of different urban design is the essence of the designer's environmental interventions, promotes the increase in consumer qualities of the environment [18]. The city is a set of symbolic and semantic systems forming an urban field. At the same time, the city structure is too vast to be subject to momentary perception. An overview of the urban environment is formed in the minds of specific fragmentary impressions, and the total perceived can create a feeling of chaos or shape in a harmonious way depending on a random or regular sequence of spatial experiences. This makes it possible to identify the main line of urban development which is the structural design of each particular local city area with solving the problem of its architectural and design characteristics taking into account its individual, authentic features $[19,20]$.

\section{Conclusions}

The most important task of our time is the formation of a design code for each city of our country within the modern standard of improvement with regard to economic opportunities, regional and historical features of the city in question. The development of environmental land register is the basis for the formation of an attractive, authentic image of the city and its socio-cultural field.

The predicted results of such an approach are the improvement of consumer quality of the environment and, accordingly, of quality of people's life, the formation of a highly aesthetic image of the city in accordance with its active role in geopolitical, economic and cultural life of Russia, increasing the investment attractiveness of peripheral areas of the city, patriotic, cultural and aesthetic education of the population aiming at eliminating vandalism and destruction, the reconstruction and formation of new iconic locations which create a unique face of Samara.

\section{References}

1. P. Bourdieu, Social Space: Field and Practice Institute of Experimental Sociology, 576 (2005)

2. I.A Dobritsina, From Postmodernism to Nonlinear Architecture, 416 (2014)

3. T.V. Karakova, Samara Scientific Center of RAS Publisher 1, $762-765$ (2015) 
4. T.V. Vavilonskaya, Strategy for Updating the Architectural and Historical Environment $368(2008)$

5. Y.S. Vorontsova, Urban Construction and Architecture 3, 49-52 (2016) doi: 10.17673/Vestnik.2016.03.8.

6. The construction and real estate $\mathbf{8 , 3 8}(2015)$

7. The construction and real estate 12, 13 (2015)

8. Materials of Improving the Urban Environment as National Development Priority Forum 10 (Moscow, 2016).

9. V.M. Melnikova, N.A. Mastalerg, Urban Construction and Architecture 1, 31-37 (2011) doi: 10.17673/Vestnik.2011.01.6.

10. N.I. Barsukova, Environmental Design in Project-Oriented Culture of Postmodernism: thesis ... Dr. of Arts (2008)

11. R. Burdette, INTERNATIONAL Project 14, 148 (2006)

12. T.V. Karakova, Volga Science Journal 3, 111-115 (2012)

13. Architecture, Construction, Design 3, 58-62 (2006)

14. T.V. Semenova, Theoretical and Applied Aspects of the Socio-Psychological Research of City Mentality: thesis ... Dr. Psychol. Sciences (2007)

15. E.A. Zaeva-Burdonskaya, The World of Science, Culture, Education 5, 94-99 (2008)

16. S. M. Mihailov, The World of Science, Culture, Education 6, 49-51 (2009)

17. A.G. Golova, Journal Of Sociology and Social Anthropology 5, 304-312 (2011)

18. T.V. Karakova, K.D. Barova, Industrial and Civil Construction 8, 11-15 (2010)

19. S.K. Nartova-Bochaver, Psychological Magazine 5, 25 (2007)

20. B. Golhoorn, Project Russia, 73 (2014) 